REVISTA DE DERECHO UNED, NÚM. 24, 2019

\title{
EL DERECHO A LA AUTONOMÍA DE LAS PERSONAS CON DIVERSIDAD FUNCIONAL*
}

\section{THE RIGHT TO AUTONOMY OF PEOPLE WITH FUNCTIONAL DIVERSITY}

\author{
GonZalo José CARBonell APARICI***
}

Resumen: El artículo pretende reflexionar sobre los fundamentos del derecho a la autonomía reclamado por el colectivo de personas con diversidad funcional desde diversas instancias. Para ello diferencia entre los conceptos de derecho fundamental y de derecho social, así como entre las distintas garantías que ofrece el derecho desde los ámbitos internacional, supranacional y nacional. Intenta por último proponer algunas vías de mejora en los recursos jurídicos disponibles, en conclusión a los apartados anteriores.

Palabras clave: vida independiente, autonomía, derecho fundamental, derecho social, derecho internacional.

Abstract: The article intends to reflect on the foundations of the right to autonomy claimed by the group of people with functional diversity from various instances. For this, it differentiates between the concepts of fundamental right and social right, as well as between the different guarantees that the law offers from the international, supranational and national spheres. Lastly, it tries to propose some ways to improve the legal resources available, in conclusion to the previous sections.

* El contenido de este artículo se basa parcialmente en una investigación doctoral presentada en la UNED con el título «La figura del Asistente Personal en el Movimiento de Vida Independiente: La experiencia en la Comunidad Valenciana». Acceso: http://e-spacio.uned.es/fez/view/tesisuned:ED-Pg-DeryCSoc-Gjcarbonell

** Graduado en Trabajo Social, Licenciado en Teología, Doctor en Derecho y Ciencias Sociales. Miembro de la Red Europea de Vida Independiente (ENIL).

(C) UNED. Revista de Derecho UNED, núm. 24, 2019 
Keywords: independent living, autonomy, fundamental right, social right, international right.

Recepción original: 04/02/2019

Aceptación original: 27/05/2019

Sumario: I. Preliminares. I.A. Diversidad funcional. I.B. El decaimiento del Estado social. I.C. El subsiguiente descontento social y la exigencia de derechos. II. El marco jurídico del derecho a la autonomía. II.A. Normativa internacional: Naciones Unidas. II.A.1. Normas generales de las Naciones Unidas. II.A.2. Normas específicas sobre diversidad funcional. II.B. Normativa regional europea. II.C. Normativa española. II.C.1. Antes de la Constitución de 1978. II.C.2. La Constitución de 19878 como base. II.C.3. Desarrollo posterior. III. El derecho fundamental a la autonomía de las personas con diversidad funcional. III.A. Derechos fundamentales. III.B. Derechos sociales. IV. Conclusiones y propuestas: La construcción del Derecho. Referencias bibliográficas.

\section{PRELIMINARES}

\section{I.A. Diversidad Funcional}

El término habitual para referirse a las personas con diversidad funcional es el de personas con discapacidad (Disability), término que aparece en los documentos supra e internacionales sobre la materia. Nosotros adoptamos este término iniciado en España por el Foro de Vida Independiente (FVID) ${ }^{1}$, como fruto de una reflexión como grupo perteneciente al Movimiento internacional de Vida Independiente (MVI) en nuestro país, que construyó el modelo de la diversidad ${ }^{2}$ como un modo idóneo de aproximación teórica a las personas con discapacidad. El término se va introduciendo en las Administraciones y en la sociedad, aunque aún sigue siendo relativamente minoritario. A nosotros nos parece un acierto elegir un término que no se fije tanto en las limitaciones de la persona como definitorio, sobre todo cuando desde la Convención sobre los derechos de las personas con discapacidad sancionada por las Naciones Unidas en 2006, se adopta abiertamente el llamado modelo social

${ }^{1}$ Cfr. http://forovidaindependiente.org/que-es-el-fvid/ (Consulta 27/01/2019) y https://es.groups.yahoo.com/neo/groups/vidaindependiente/conversations/topics/9622 (Consulta 27/01/2019)

2 FERREIRA, M.A.V., "De la minus-valía a la diversidad funcional: Un nuevo marco teórico-metodológico», Política y Sociedad, vol. 47, n. 1, 2010, págs. 45-65. 
de la discapacidad ${ }^{3}$. Este modelo pone el acento en la responsabilidad social que provoca un tipo de situaciones discapacitantes al no ofrecer las oportunas infraestructuras para que puedan ser utilizadas por personas divergentes de lo estandarizado, con características diversas, físicas o cognitivas, que tienen también derecho a ser incluidas en una sociedad, todavía con un marcado acento capacitista $(\text { Ableism })^{4}$. Todos tenemos algo en común, pero a la vez somos diferentes. Es evidente que si construimos escaleras no podrán subir por ellas personas que deben desplazarse con sillas de ruedas, a no ser que pongamos los oportunos ascensores o rampas, que hacen posible que estos colectivos sean capaces de subir a donde antes se les habría discapacitado a la hora de planificar un edificio público o privado.

Nuestra postura personal es la consideración del modelo social en tres vertientes: el modelo de Vida Independiente, el modelo social propiamente dicho, y el modelo de la diversidad. De este modo, se ve reflejada la esencia del ser humano, a la vez individual, social y diverso, formando una sociedad en la que todos somos interdependientes de una forma $\mathrm{u}$ otra, pero a la que todos podemos aportar nuestra propia idiosincrasia. Y, lo que es más importante, una posición desde la cual podemos reclamar nuestros derechos individuales y sociales como una unidad inseparable ${ }^{5}$.

\section{I.B. El decaimiento del Estado Social}

La definición del Estado como social y democrático de Derecho es el principio central del orden político contemporáneo del capitalismo desarrollado a partir de la Segunda Guerra Mundial ${ }^{6}$. Es en este contexto donde nace y se desarrolla el modelo social, porque es justo en este modelo de Estado donde puede manifestarse la solida-

3 PALACIOS, A., El modelo social de discapacidad: orígenes, caracterización y plasmación en la Convención Internacional sobre los Derechos de las Personas con Discapacidad, Cinca, Madrid, 2008.

4 Sobre este importante concepto, cfr. TOBOSO MARTÍN, M. 2017, «Capacitismo" en PLATERO, R.L. et al. (eds.), Barbarismos queer y otras esdrújulas, Bellaterra, Barcelona, 2017, pp. 73-81; Cfr. https://ableism.wordpress.com/ableism-bibliography/ (Consulta 26/01/2019).

5 CARBONELL APARICI, G.J. La figura del asistente personal en el Movimiento de Vida Independiente: La experiencia en la Comunidad Valenciana. Tesis Doctoral (en línea). UNED, 2018, págs. 99-100. Acceso: http://e-spacio.uned.es/fez/eserv/ tesisuned:ED-Pg-DeryCSoc-Gjcarbonell/CARBONELL_APARICI_Gonzalo_Jose_Tesis.pdf (Consulta 27/01/2015.).

${ }^{6}$ DE CABO MARTÍN, C., La crisis del Estado Social, PPU, Barcelona, 1986, pág. 16. 
ridad como un agente corrector de la desigualdad social, provocada en su base por un sistema económico que redunda en beneficio de los más «fuertes». Entre los «débiles» ha estado siempre el colectivo de personas con diversidad funcional, dependientes de sus familias y de una eventual asistencia social altruista o religiosa ${ }^{7}$. Pero la entrada de los "débiles» en las Constituciones como norma suprema de estos Estados supone rupturas significativas con el sistema garantista anterior: 1) ruptura con el universalismo del concepto de sujeto, reconociendo el derecho a la diferencia; 2) ruptura de la subjetividad como fundamento exclusivo del derecho, al introducir un elemento objetivo que reconoce la debilidad; y 3) ruptura del individualismo como principio dominante, dando entrada a lo colectivo, como ocurre en otras culturas no occidentales, como elemento conformador de lo individual ${ }^{8}$.

Pero el Estado social y las políticas de bienestar que le acompañaban, apoyándose en las doctrinas keynesianas en un momento económicamente productivo, no han podido superar la crisis fiscal del Estado dentro de una sociedad cada vez más globalizada económica y tecnológicamente, teniendo que frenar el desarrollo social en aras de una deseada estabilidad financiera a escala internacional, regional y nacional. La reforma del artículo 135 de nuestra constitución española (CE), que obliga las Administraciones Públicas a adecuar sus actuaciones al principio de estabilidad presupuestaria, es una muestra evidente de esta situación contradictoria9 .

\section{I.C. El subsiguiente descontento social y la exigencia de derechos}

Los recortes en derechos sociales han provocado una serie de reacciones más o menos violentas reclamando los derechos que se consideran perdidos en pro de una pretendida estabilidad financiera. En el terreno de la diversidad funcional, que es la que aquí nos ocupa, el MVI fue un luchador nato en favor de su derecho civil de independencia, entendida esta como el derecho a controlar su pro-

${ }^{7}$ AGUADO DÍAZ, A.L., Historia de las Deficiencias, Escuela Libre Editorial, Madrid, 1995.

${ }^{8}$ DE CABO MARTÍN, C., Teoría constitucional de la Solidaridad, Ediciones Jurídicas y Sociales, S.A., Madrid, 2006, págs. 65-66; estas «rupturas» serían relativas, más bien «desplazamientos». Cfr. FERRAJOLI, L., Derechos y garantías. La ley del más débil, Trotta, Madrid, ed. 2004.

9 Cfr. B.O.E., núm. 233, de 27 de septiembre de 2011; MAESTRO BUELGA, G., «El Estado Social 40 años después: la desconstitucionalización del programa constitucional», Revista de Derecho Político, n. 100, 2017, págs. 766-798. 
pia vida, dentro del marco de la sociedad estadounidense. Su vocación internacional sin embargo, muy pronto se vio enriquecida con las aportaciones de otros países como Gran Bretaña o Suecia, mucho más sensibilizados en los derechos sociales en el marco común europeo, asumiendo una labor internacional de apoyo a los países más débiles, como lo demuestra la creación de la Red Europea de Vida Independiente (ENIL), o el liderazgo del Movimiento en Japón en apoyo a programas de Vida Independiente en países menos desarrollados. La actitud del MVI ha sido siempre crítica con los Gobiernos, y sus logros han dependido en gran medida de las políticas de bienestar que se podían permitir los Estados en relación a sus deudas externas, pero también a la conciencia social ciudadana. Por lo tanto, hoy pugnan por mejorar unas leyes con suficientes garantías en favor de lo que consideran sus derechos como seres humanos. En España han llegado a elaborar una propuesta de ley orgánica, a favor de la asistencia personal, una de sus principales reivindicaciones de cara a su autonomía, que han presentado como proyecto al Comité español de representantes de las personas con discapacidad (CERMI), que es la entidad española que representa los intereses de todo el colectivo ${ }^{10}$.

El CERMI por su parte, ya hace años que promueve campañas de sensibilización y protesta contra los recortes sociales, entre los que destacamos muy en especial la campaña para constitucionalizar como derechos fundamentales los derechos de las personas con discapacidad $^{11}$. Esta línea de reivindicación nos parece muy adecuada, dado que apelar a los derechos humanos e incluso construir un modelo de aproximación a la discapacidad basados en ellos, nos parece hablar de un metamodelo al que todo modelo tiende, pero que en la práctica puede quedar, hoy por hoy, vacío de garantías, si no se asienta en los derechos fundamentales avalados por la Constitu-

${ }^{10}$ Cfr. FVID. Carta abierta a Luis Cayo Pérez Bueno, presidente del Cermi estatal, FVID, 7 diciembre, 2018. Acceso: http://forovidaindependiente.org/carta-abierta-aluis-cayo-perez-bueno-presidente-del-cermi-estatal/ (Consulta 26/01/2019). En Esta carta se pone el enlace directo con la propuesta de ley: Acceso: https://drive.google. com/file/d/1VQAMG5zoyjopiA9i-8cLifeYx_YdpxUK/view?usp=sharing (Consulta 26/01/2019).

${ }^{11}$ CERMI. El CERMI plantea la constitucionalización como fundamentales de los derechos sociales, CERMI, Madrid, 20/08/2015. Acceso: https://www.cermi.es/es/ actualidad/noticias/el-cermi-plantea-la-constitucionalizaci\%C3\%B3n-como-fundamentales-de-los-derechos (Consulta (27/01/2019); CERMI. El CERMI pide en el Senado incluir los derechos sociales como fundamentales en la Constitución, Madrid, CERMI, 20/09/2017. Acceso: https://www.cermi.es/es/actualidad/noticias/el-cermipide-en-el-senado-incluir-los-derechos-sociales-como-fundamentales-en (Consulta 26/01/2019).

(C) UNED. Revista de Derecho UNED, núm. 24, 2019 
ción de cada país ${ }^{12}$. Por tanto, creemos que es imprescindible comprender la dinámica de los derechos y sus garantías en sus diferentes marcos (internacional, supranacional y nacional) que, en conjunto, conforman nuestra calidad de vida.

\section{EL MARCO JURIDICO DEL DERECHO A LA AUTONOMÍA}

Nuestro planteamiento global invita a comenzar este apartado desde el punto de vista del Derecho internacional, cuya influencia y eficacia normativa resultan cada vez más cotidianas. De acuerdo con las propias Constituciones nacionales (arts. 10.2 y 96.1 CE), los Tratados internacionales ratificados nos afectan directamente ${ }^{13}$.

\section{II.A. Normativa internacional: Naciones Unidas}

\section{II.A.1. Normas generales de las Naciones Unidas}

El nombre de «Naciones Unidas» fue acuñado por el Presidente Roosevelt y se utilizó por primera vez el 1 de enero de 1942, durante la segunda guerra mundial, cuando representantes de 26 naciones aprobaron la «Declaración de las Naciones Unidas», en virtud de la cual sus respectivos gobiernos se comprometían a seguir luchando juntos contra las Potencias del eje Roma-Berlín-Tokio. En 1945, representantes de 50 países se reunieron en San Francisco en la Conferencia de las Naciones Unidas sobre Organización Internacional, para redactar la Carta de las Naciones Unidas, que fue firmada el 26 de junio. Polonia, que no estuvo representada, la firmó más tarde y se convirtió en uno de los 51 Estados Miembros fundadores. Las Naciones Unidas empezaron a existir oficialmente el 24 de octubre de 1945, después de que la Carta fuera ratificada por la mayoría de los países firmantes. Con esta Carta, la comunidad internacional se comprometió a no permitir nunca más atrocidades como las sucedidas en la gran guerra. El Estatuto de la Corte Internacional de Justicia es parte integrante de esta Carta, comenzando así el camino hacia un verdadero Derecho internacional operativo.

12 Cfr. CAMPOY CERVERA, I., "La construcción de un modelo de derechos humanos para niños, con o sin discapacidad», Derechos y libertades: Revista del Instituto Bartolomé de las casas, n. 37, 2017, págs. 131-165.

13 Cfr. GUTIÉRREZ GUTIÉRREZ, I. (dir.), Elementos de Derecho constitucional español, Marcial Pons, Madrid, ed. 2015, págs. 244-250. 
Los líderes del mundo decidieron complementar la Carta de las Naciones Unidas con una Declaración acerca de los derechos válidos para todas las personas en cualquier lugar y en todo momento. El 10 de diciembre de 1948, la Asamblea General de las Naciones Unidas reunida en París, aprobó la Declaración Universal de Derechos Humanos. Esta Declaración, junto con el Pacto Internacional de Derechos Económicos, Sociales y Culturales (PIDESC) y el Pacto Internacional de Derechos Civiles y Políticos (PIDCP), con sus respectivos protocolos facultativos, ambos de fecha 16 de diciembre de 1966, conforman la Carta Internacional de Derechos Humanos. En conjunto y hasta la entrada en vigor de los Pactos en 1976, se concreta en un plazo temporal de casi treinta años. Debe recordarse, en cualquier caso, que estos Tratados no crean por sí mismos derechos subjetivos que los particulares puedan invocar ante los tribunales, sino tan solo compromisos de los Estados Partes para tomar medidas que los hagan efectivos.

Teniendo en cuenta esta última consideración hay que puntualizar que los dos citados Pactos nacen con una asimetría importante:

Cada Estado Parte se compromete a adoptar, con arreglo a sus procedimientos constitucionales y a las disposiciones del presente Pacto, las medidas oportunas para dictar las disposiciones legislativas o de otro carácter que fueren necesarias para hacer efectivos los derechos reconocidos en el presente Pacto y que no estuviesen ya garantizados por disposiciones legislativas o de otro carácter (art.2.2 PIDCP).

Cada uno de los Estados Partes en el presente Pacto se compromete a adoptar medidas, tanto por separado como mediante la asistencia y la cooperación internacionales, especialmente económicas y técnicas, hasta el máximo de los recursos de que disponga, para lograr progresivamente, por todos los medios apropiados, inclusive en particular la adopción de medidas legislativas, la plena efectividad de los derechos aquí reconocidos (art.2.1 PIDESC) [subrayados nuestros].

Como vemos en el segundo texto, el art. 2.1 PIDESC se refiere al principio de progresividad, cuya obligación mínima sería la no regresividad $^{14}$, junto con el llamado principio de reserva de lo posible. Ambos principios constituyen una cuestión recurrente en la

${ }^{14}$ Este es un aspecto discutido, pero de una amplia aceptación, cuyo exponente máximo sería la teoría de la irreversibilidad de los derechos sociales, con la consiguiente prohibición de regresividad (Nichtumkehrbarkeitstheorie). Cfr. HESSE, K., Grundzüge des Verfassungsrechts der Bundesrepublik Deutschland, C. F. Müller $\mathrm{GmbH}$, Heidelberg-Karlsruhe, ed. 1978. Citado por ABRAMOVICH, V. y COURTIS, CH., Los derechos sociales como derechos exigibles, Trotta, Madrid, ed.2014, p.95 en nota 46.

(C) UNED. Revista de Derecho UNED, núm. 24, 2019 
discusión sobre el contenido y alcance de los derechos sociales y explican parcialmente el decaimiento de Estado social al que hemos aludido ${ }^{15}$.

\section{II.A.2. Normas específicas sobre diversidad funcional}

El primer instrumento jurídico internacional que hace referencia a las personas con diversidad funcional se remonta al año 1950, con la Resolución aprobada por el Consejo Económico y Social de Naciones Unidas, entre otras cosas, sobre «rehabilitación social de las personas físicamente impedidas ${ }^{16}$, lo que supone un salto cualitativo desde la beneficencia a la perspectiva rehabilitadora y médica.

El primer texto declarativo de derechos específicos sobre personas con diversidad funcional (aunque restringido a la discapacidad mental) surge en 1971, con la Declaración de los derechos del Retrasado Mental ${ }^{17}$. La Declaración de los derechos de los impedidos de 1975 amplía el horizonte a la «incapacidad física y mental», convirtiéndose así en el primer instrumento "genérico» de las personas con diversidad funcional ${ }^{18}$.

En 1976, la Asamblea General de Naciones Unidas proclama el año 1981 como Año Internacional de los Impedidos. Quizá el mejor fruto de este año internacional fuera generar una reflexión general sobre el colectivo que, con el tiempo, llevaría hacia un cambio de las actitudes sociales hacia el paradigma social de la diversidad funcional. Resultado también de este año fue el «Programa de ac-

15 PERLINGEIRO R., "¿La reserva de lo posible se constituye en un límite a la intervención jurisdiccional en las políticas públicas sociales?», Estudios Socio-Jurídicos, vol. 16, n.2, 2014, págs. 181-212; GARGARELLA, R., "Primeros apuntes para una teoría sobre los derechos sociales. ¿Es posible justificar un tratamiento jurídico diferenciado para los derechos sociales e individuales?», Jueces para la democracia, n. 31, 1998, págs. 11-15.

${ }^{16}$ NACIONES UNIDAS. Consejo Económico y Social, Resolución sobre Rehabilitación social de las personas físicamente impedidas E/1849: 309 (XI) E, pág. 20, de 13 de julio de 1950.; Cfr. SANJOSÉ GIL, A., "El primer tratado de derechos humanos del siglo XXI: La Convención sobre los derechos de las personas con discapacidad», Revista electrónica de estudios internacionales, n. 13, 2007, pág. 4.

17 NACIONES UNIDAS, Declaración de los derechos del retrasado mental. Resolu-

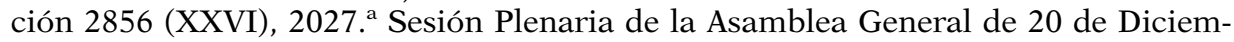
bre de 1971.

18 Para todos los documentos, sobre las personas con diversidad funcional hasta la Convención de 2006 incluida, se puede consultar el siguiente enlace de las Naciones Unidas: http://www.un.org/spanish/documents/instruments/docs_subj_ sp.asp?subj=16 (Consulta 26/01/2019). 
ción mundial para los impedidos» ${ }^{19}$, un trabajo ya muy elaborado en comparación con anteriores documentos y que puede considerarse como la primera guía general de políticas y directrices en los diferentes contextos del mundo. En esta misma resolución se proclama 1983-1992 Decenio de las Naciones Unidas para los Impedidos, que fue motor de un gran número de acciones y estudios encaminados a reforzar los derechos de las personas con diversidad funcional.

Entre las actividades de este decenio destacan las llamadas «Directrices de Tallinn para el desarrollo de los recursos humanos en la esfera de los impedidos». Esta Reunión internacional se celebró del 14 al 22 de Agosto de 1989 y en ella se subraya entre otras cosas la necesidad del reconocimiento jurídico de los derechos de las personas con diversidad funcional, de la eliminación de barreras, de la plena participación y promoción de iniciativas de base, de programas específicos de capacitación y acceso al empleo, de la creación de fondos nacionales para realizar los programas, de la sensibilización comunitaria y la cooperación a nivel internacional.

El Decenio de las Naciones Unidas para los Impedidos, sin embargo, no cumplió con todos sus objetivos; no llegó a una Convención Internacional, aunque sí se aprobaron en 1993 las llamadas «Normas Uniformes sobre igualdad de oportunidades para las personas con discapacidad $»^{20}$. Estas Normas, aún con un claro enfoque rehabilitador (arts. 2 y 3), incorporan la perspectiva de los derechos humanos y hacen mayor hincapié en aspectos fundamentales como la igualdad de oportunidades orientada hacia la plena participación social, aludiendo expresamente en su artículo 4 a las asistencia personal. Aunque sin efecto vinculante, se constituyeron así en el instrumento guía más importante en el siglo xx en lo referente a las políticas sobre diversidad funcional.

La Convención de Naciones Unidas sobre los derechos de las personas con discapacidad de 2006 es el primer instrumento amplio de derechos humanos del siglo Xxi, y el primer Tratado de derechos humanos que se abre a la firma de las organizaciones regionales de integración. Pero, sobre todo, señala un cambio paradigmático en las actitudes y enfoques teóricos respecto a las per-

19 NACIONES UNIDAS, Programa de Acción Mundial para los Impedidos. Resolución 37/52 de 3 diciembre 1982.

${ }^{20}$ NACIONES UNIDAS, Normas Uniformes sobre la igualdad de oportunidades

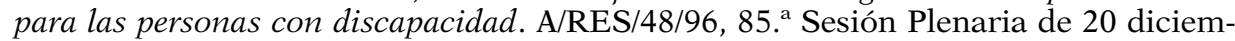
bre, 1993. 
sonas con discapacidad: la Convención se concibió como un instrumento de derechos humanos con una dimensión explícita de desarrollo social. En ella se adopta un concepto abierto para referirse a las personas con discapacidad y se reafirma que todas las personas con cualquier tipo de discapacidad deben poder gozar de todos los derechos humanos y libertades fundamentales. Se aclara y precisa cómo se aplican a las personas con discapacidad todas las categorías de derechos y se indican las esferas en las que es necesario introducir adaptaciones para que las personas con discapacidad puedan ejercerlos de forma efectiva, así como las esferas en las que más se han vulnerado y en las que, consecuentemente, debe reforzarse la garantía de protección ${ }^{21}$.

La popularidad de la Convención entre las personas con diversidad funcional se pudo deber a la gran participación que tuvieron en su preparación y desarrollo, promovida por el Comité Especial, que abrió sus puertas a nivel mundial a todo movimiento asociativo que les representase. Esto hizo posible registrar un cambio en la percepción de la discapacidad por parte de la sociedad, pero también y sobre todo por parte del mismo colectivo, cuya autopercepción había cambiado notablemente y se constituyó en la causa última del cambio normativo posterior. El MVI fue y sigue siendo parte importante en la gestación de este cambio. Los miembros del FVID, en su carta de presentación, se ven a sí mismos como veladores por el cumplimiento de la Convención de la ONU. En general, todas las Asociaciones de las personas con diversidad funcional consideran la labor de difusión de esta Convención como una prioridad y las entidades más representativas forman parte de una comisión de evaluación sobre la aplicación de la Convención existente en los países firmantes. El representante oficial para España, también como velador del cumplimiento de esta Convención, es el CERMI.

Del contenido específico de la Convención, y ya en relación directa con el tema de este trabajo, importa en primer lugar mencionar el art. 12, "Igual reconocimiento como persona ante la ley», que tiene gran transcendencia sobre todo en lo referente a las personas con diversidad cognitiva. En él se reconoce la personalidad jurídica de las personas con discapacidad, así como su capacidad jurídica en igualdad de condiciones. Según García Pons, este artículo unifica la capacidad jurídica y la capacidad de obrar en un todo inseparable, de modo que supone un cambio en las legislaciones nacionales pro-

${ }^{21}$ Cfr. Introducción de las Naciones Unidas al texto de la Convención en http:// www.un.org/spanish/disabilities/default.asp? navid=13\&pid=497 (Consulta 27/01/2019). 
clives a la incapacitación y a la sustitución de los interesados por representantes legales ${ }^{22}$.

Por otra parte, el art. 19, «Derecho a vivir de forma independiente y a ser incluido en la comunidad», es uno de los artículos de la Convención más valorados por el MVI. Es el único artículo donde se menciona expresamente la asistencia personal, contextualizándolo con los derechos de participación, inclusión y vida independiente, más allá de los cuidados familiares. En los tres apartados de este artículo se hace referencia: 1) al derecho a la libertad de decisión sobre cómo y dónde vivir frente un internamiento involuntario, en conexión con el art. 12 sobre la plena capacidad de obrar; 2) al derecho a los apoyos necesarios en todas las circunstancias dentro o fuera del hogar, para poder ejercer cualquiera de sus derechos. Entre estos apoyos se incluye la asistencia personal que sea necesaria; 3) a la necesidad de accesibilidad para que la inclusión sea efectiva, como se reconoce en el art. 9, siendo una seña de identidad del modelo social de acercamiento a la diversidad funcional.

\section{II.B. Normativa regional europea}

En el marco del Consejo de Europa, la protección de los derechos humanos de las personas con discapacidad se articula en torno a dos instrumentos fundamentales que gozan de eficacia jurídica como normas de Derecho Internacional: a) la Convención Europea para la Protección de los Derechos Humanos y Libertades Fundamentales de 1953 y sus Protocolos (en especial el Protocolo XI, que modifica el sistema de protección sobre los derechos civiles y políticos), y que en su art. 19 crea el Tribunal Europeo de Derechos Humanos; b) la Carta Social Europea y sus Protocolos —incluida la Carta Social Europea Revisada de 1996- fundamentalmente en lo que atañe a la protección de los derechos sociales.

Con respecto a la diversidad funcional, el Acuerdo parcial en el campo de salud social y pública adoptado el 16 de Noviembre de 1959 creó un Comité de expertos que garantizasen la cooperación entre los Estados firmantes, de modo que se intentara superar el concepto de salud estrictamente sanitaria y rehabilitadora para ir hacia un concepto integral de inclusión social y disfrute igualitario

${ }^{22}$ GARCÍA PONS, A., «El artículo 12 de la Convención de Nueva York de 2006 sobre los Derechos de las Personas con Discapacidad y su impacto en el Derecho Civil de los Estados signatarios: el caso de España», $A D C$, tomo LXVI, fascículo I, 2013, pág. 78. 
de los derechos humanos ${ }^{23}$. En 2016 se crea la Estrategia 2017-2023, que refuerza la inclusión participativa y refuerza aspectos específicos de la antidiscriminación, como la discriminación múltiple, de género, la accesibilidad universal y la sensibilidad social. Son principios generales que cada país ha de adaptar a su situación específica.

Por su parte, la jurisprudencia del Tribunal Europeo de Derechos Humanos tiene un importante peso específico, porque es la única jurisdicción internacional de derechos humanos a la que pueden acudir directamente los particulares que demandan a los Estados firmantes de un Tratado internacional. Sus sentencias, aunque sean en principio solo declarativas, se consideran obligatorias y vinculan a los Estados. Ha tratado ocasionalmente temas relacionados con la diversidad funcional, aunque la ficha informativa elaborada por los servicios del Tribunal encuadra sus aportaciones, significativamente, bajo el epígrafe de «salud». Los casos ahí recopilados se refieren a cuestiones de discriminación, a esterilizaciones o tratamientos médicos involuntarios, a la libertad de residencia y de formar una familia y a otros temas similares, que, ciertamente, coinciden en líneas generales con la Convención de 2006.

En el marco de la Unión Europea (UE), el Derecho tiene dos niveles básicos. El Derecho originario está formado por los Tratados constitutivos de la Unión, que dan vida a sus instituciones. Actualmente los Tratados en vigor son fundamentalmente dos: el Tratado de la Unión Europea (TUE) y el Tratado de Funcionamiento de la Unión Europea (TFUE); en el art. 1 de ambos se expresa que los dos Tratados constituyen el fundamento de la UE y tienen el mismo valor jurídico; pero el art. 6.1 añade que también la Carta de Derechos Fundamentales de la Unión tiene el mismo valor que los Tratados, por lo que se debe considerar parte del Derecho originario.

El TFUE hace dos referencias expresas a la diversidad funcional en los artículos 10 y 19, ambas en relación con el principio de no discriminación en razón de discapacidad u otros motivos que se enumeran, así como a las necesarias acciones para hacerlo efectivo por parte de la UE y en apoyo de las iniciativas nacionales. La mayor parte de los artículos del Tratado tienen un trasfondo económico, reflejo de sus orígenes como Comunidad Económica Europea; la libre circulación de personas, como la de mercancías, capitales y servicios están pensadas en este sentido inicial, así como las políticas so-

${ }^{23}$ CARBONELL APARICI, G.J., «La asistencia personal, una herramienta saludable para las personas con diversidad funcional», en MARCOS DEL CANO, A.M. (dir.), El derecho a una asistencia sanitaria para todos: Una visión integral, Dykinson, Madrid, 2017, pp. 411-425. 
ciales que nacen en relación con el trabajo y en referencia a la Carta Social Europea (1961) y la Carta comunitaria de los derechos sociales fundamentales de los trabajadores (1989) (arts. 82 ss.); también el art. 151 sobre la lucha contra la exclusión y el art. 162 acerca de la coordinación entre los Estados en sus políticas laborales. El Fondo Social Europeo nace también para fomento del empleo, la movilidad laboral y la adaptación de normas a las nuevas circunstancias de mercado (art.162). Se ve en todo ello una clara apuesta por la inclusión ciudadana a través de la integración laboral más que por la prestación social.

La Carta Europea de Derechos Fundamentales, sin embargo, no solo se abre con la proclamación de que «la dignidad humana es inviolable. Será respetada y protegida» (art. 1), sino que en ella se recoge el principio de igualdad (art. 20), la interdicción de discriminación con referencia específica a la discapacidad (art. 21) y, en el art. 26, un principio general de «integración de las personas discapacitadas»: «La Unión reconoce y respeta el derecho de las personas discapacitadas a beneficiarse de medidas que garanticen su autonomía, su integración social y profesional y su participación en la vida de la comunidad».

En el Derecho derivado tiene especial relevancia la Convención de las Naciones Unidas sobre los Derechos de las Personas con Discapacidad de 2006, que fue ratificada por la UE el 23 de diciembre de 2010, pasando así a ser Derecho convencional de la Unión. También se integran en él los programas en favor de las personas con diversidad funcional, las estrategias europeas generales, como la estrategia 2010-2020 sobre discapacidad, centrada en la eliminación de barreras, la sensibilización y la recopilación de datos. Son relevantes los pronunciamientos del Tribunal de Justicia Europeo una de cuyas recientes sentencias (25/07/2018) se pronuncia a favor de la asistencia personal en el caso de estudios de un usuario fuera de su país, dentro de la $\mathrm{UE}^{24}$.

Hay que subrayar la importancia de Agencia de la Unión Europea para los derechos fundamentales (FRA), que proporciona a los responsables de la toma de decisiones nacionales y de la UE asesoramiento independiente, contribuyendo así a que los debates, las políticas y la legislación en materia de derechos fundamentales estén mejor informados y sean más específicos. El FRA trabaja

${ }^{24}$ Referencia: ECLI:EU:C:2018:601. ENIL, sin embargo, considera insuficientes los fundamentos jurídicos que presenta a favor. Cfr. http://enil.eu/news/ecj-rules-infavour-of-personal-assistance/ (Consulta 01/02/2019). 
en colaboración con las instituciones europeas e internacionales, así como con grupos y organizaciones que se ocupen de derechos fundamentales por medio de la Plataforma de los Derechos Fundamentales.

Uno de sus focos de atención está constituido por las personas con discapacidad y la implementación de los derechos proclamados por la Convención de 2006, entre los que destaca el artículo 19, sobre el derecho a la vida independiente, y que plasma en una serie de publicaciones sobre este tema, así como en una serie de informes que inciden especialmente en la desinstitucionalización de las personas con diversidad funcional y la accesibilidad universal. Además, en el informe presentado sobre la implementación de los derechos en el año 2017 habla expresamente de la asistencia personal refiriéndose a ella como el único tipo de servicio de apoyo comunitario específico mencionado en el art.19, atribuyendo a la refamiliarización de los cuidados y a la política de recortes sociales el ser la causa principal de la menor implementación del artículo 19.

\section{II.C. Normativa española}

\section{II.C.1. Antes de la Constitución de 1978}

Hasta el siglo XIX no se formularon en España políticas públicas ante problemas sociales ${ }^{25}$. Anteriormente se asumía que el Estado debía garantizar el orden público, y las leyes de pobres tenían más bien un sentido represor, con intención de impedir la mendicidad. La atención directa a los pobres (donde se incluía a las personas con diversidad funcional) era cuestión de caridad cristiana o beneficencia estatal en albergues o casas de misericordia ${ }^{26}$. La Constitución Española de 1812 reconoce la responsabilidad de la Administración en atención social, atribuyendo a los Ayuntamientos competencias en la atención a los pobres y a las Diputaciones el correspondiente control (arts. 321.6 y 335.8) ${ }^{27}$. La ley de Beneficencia de 1822 desarrolla la Constitución de 1812 con las Juntas Municipales y Parroquiales, en un intento de institucionalizar un sistema de

${ }^{25}$ JIMÉNEZ LARA, A. y HUETE GARCÍA, A., «Políticas públicas sobre discapacidad en España. Hacia una perspectiva basada en los derechos», Política y Sociedad, vol. 47, n.1, 2010, págs. 137-152.

${ }^{26}$ Cfr. ALEMÁN BRACHO, C. (coord.), Fundamentos de servicios sociales, Tirant lo Blanch Valencia, 2010.

${ }^{27}$ Constitución política de la monarquía española. Promulgada en Cádiz a 19 de Marzo de 1812. 
protección ${ }^{28}$. En el «Reglamento general para la ejecución de la ley de beneficencia de 20 de Junio de 1849», en su art. 5, ya se prevé expresamente la disposición de establecimientos para personas con diversidad funcional ${ }^{29}$. Sin embargo, la beneficencia liberal, como antes el Antiguo régimen, se asentaba en último término en la caridad cristiana, utilizándose como instrumento más de control que para la promoción social.

La Comisión de Reformas Sociales (1883) se considera el verdadero germen de las políticas sociales en España, fruto del surgimiento de la cuestión social obrera nacida en Europa con el industrialismo y más tardíamente en España. A pesar de reflejar la preocupación por el lamentable estado social y referirse a temas como la discapacidad por accidentes laborales, nunca se llamó a la participación directa de los obreros en dicha Comisión. En 1886, en un real decreto "aprobatorio del pliego de condiciones generales para la contratación de las obras públicas», se aprueba en su artículo 16 la obligación de asegurar a los operarios de los accidentes laborales, en la línea bismarckiana de seguro profesional iniciado dos años antes en Alemania y que da pie a un determinado modelo de bienestar. En 11 de enero de 1887 se publica un real decreto para la creación de un asilo para inválidos del trabajo. En 30 de enero de 1900 se promulga la Ley de accidentes de trabajo, que incorpora el principio de riesgo profesional al ordenamiento español. Ya en 1908 se crea el Instituto Nacional de Previsión, aún en la línea de beneficencia, precursor de la Seguridad Social, creándose paulatinamente seguros sociales específicos.

Con el objetivo principal de implantar un modelo unitario e integrado de protección social se aprobó en 1963 la Ley de Bases de la Seguridad Social, que en su base decimoquinta sobre «Servicios sociales», en su apartado C), habla de "Reeducación y rehabilitación de inválidos». La Ley General de la Seguridad Social de 1966 supone el nacimiento de la Seguridad Social moderna, con gran número de artículos dedicados a los accidentes y enfermedades laborales, a los

${ }^{28}$ Ley de Beneficencia de 1822. Decreto de Cortes de 21/12/1821. Acceso: https:// docs.google.com/document/d/1 zrSiklqWMq_7E-1FpXhvF56Q2FqO-3ND6ILrTRZrD54/edit (Consulta 28/01/2019).

${ }_{29}$ Reglamento general para la ejecución de la ley de beneficencia de 20 de Junio de 1849, decreto de 14/05/1852. Gaceta de Madrid, núm. 6537 de 16/05/1852, pp. 2-4. El art. 5 dice: «El Gobierno, oída la Junta general de beneficencia, señalará los puntos donde hayan de situarse los establecimientos generales. Su número será por ahora en todo el reino de seis casas de dementes, dos de ciegos, dos de sordo-mudos, y diez y ocho de decrépitos, imposibilitados e impedidos». Cfr. Ley General de Beneficencia, de 20 de junio de 1849. Gaceta de Madrid, 24/06/1849, n. 5398.

() UNED. Revista de Derecho UNED, núm. 24, 2019 
tipos de invalidez y sus prestaciones, a las prestaciones subsidiarias de servicios sociales, a la rehabilitación y reeducación de inválidos; todo ello se mantiene dentro del contexto laboral, base de la Seguridad Social.

Más allá de esto, y respecto a las personas con diversidad funcional, por el Real Decreto de 22 Enero de 1910 se crea el Patronato Nacional de sordomudos, ciegos y anormales, de carácter consultivo, para el Ministerio de Instrucción Pública y Bellas Artes, antecedente del actual Real Patronato sobre Discapacidad. A instancias del Real Patronato surgen el Plan Nacional de Prevención de la Subnormalidad y el Plan Nacional de Educación Especial, ambos en 1978, o en 1983 el Plan Nacional de Empleo para deficientes, siguiendo con una encomiable labor hasta nuestros días.

\section{II.C.2. La Constitución de 1978 como base}

La Constitución Española de 1978 puede dar pie a un cambio en los modos de abordar la diversidad funcional. El art. 14 sienta como base genérica el principio de no discriminación, fundamental para la igualdad de oportunidades en el ámbito de la diversidad funcional. En el art. 9.2 se habla, también en sentido genérico, de la obligación de los poderes públicos de promover las condiciones y eliminar los obstáculos que impidan la plena participación ciudadana en condiciones de igualdad. También hay que recordar el art. 149.1.1. ${ }^{\mathrm{a}}$ : «El Estado tiene competencia exclusiva sobre las siguientes materias: $1 .^{\mathrm{a}} \mathrm{La}$ regulación de las condiciones básicas que garanticen la igualdad de todos los españoles en el ejercicio de los derechos y en el cumplimiento de los deberes constitucionales», que cabe entender como delimitación de las competencias autonómicas en el ámbito de los servicios sociales, donde se ubica la atención a la diversidad funcional.

Sólo hay un precepto que hace referencia explícita a la diversidad funcional, el art. 49: «Los poderes públicos realizarán una política de previsión, tratamiento, rehabilitación e integración de los disminuidos físicos, sensoriales y psíquicos a los que prestarán la atención especializada que requieran y los ampararán especialmente para el disfrute de los derechos que este Título (Título I: De los derechos y deberes fundamentales) otorga a todos los ciudadanos» ${ }^{30}$, aceptando explícitamente el principio de igualdad.

${ }^{30}$ Subrayado nuestro. 
La interpretación del precepto habrá de partir de la consideración de la $\mathrm{CE}$ como norma suprema lo suficientemente abierta como para asumir cambios en el desarrollo de los derechos que ella considera fundamentales (con mayores garantías), pero al mismo tiempo lo suficientemente estable como para no vincularse a una determinada concepción política de las tareas públicas. Nuestra tarea ahora será ver cómo se han puntualizado los derechos sugeridos con respecto a la diversidad funcional y su armonización con la posterior Convención de 2006, en correspondencia a su art. 10.2, que reconoce el peso interpretativo de los Tratados internacionales ratificados por España.

\section{II.C.3. Desarrollo posterior}

Como desarrollo de la CE, se adoptaron importantes leyes con referencia a la diversidad. La Ley 13/1982, de 7 de abril, de integración social de los minusválidos (LISMI) ${ }^{31}$, se basa en el art. $49 \mathrm{CE}$ y en el «Programa de Acción Mundial para los Impedidos» publicado ese mismo año ${ }^{32}$, donde la «equiparación de oportunidades» (arts. $21 \mathrm{al}$ 30) tiene un lugar central para suplir las deficiencias de un modelo rehabilitador: se hacen necesarios apoyos complementarios, ayudas técnicas y servicios. La LISMI crea un sistema de prestaciones sociales para quienes no estuvieran bajo cobertura de la Seguridad Social, vinculada al trabajo, modelo que sería consolidado posteriormente por la Ley de prestaciones no contributivas de $1990^{33}$. Impulsó importantes políticas de integración con los Centros Especiales de Empleo ${ }^{34}$ y la cuota de reserva de empleo, dando rango legal al Decreto 2531/1970, de 22 de agosto, sobre empleo de trabajadores minusválidos ${ }^{35}$. También abre la puerta a la participación del sector privado en los servicios sociales del Estado, como p.e. en los Centros ocupacionales $^{36}$.

${ }^{31}$ BOE núm. 103, de 30/04/1982. Esta ley fue derogada por Real Decreto Legislativo 1/2013, de 29 de noviembre, por el que se aprueba el Texto Refundido de la Ley General de derechos de las personas con discapacidad y de su inclusión social. (BOE núm. 289, de 03/12/2013).

32 Naciones Unidas. Resolución 37/52 de 3 diciembre 1982.

33 Ley 26/1990, de 20 de diciembre, por la que se establecen en la Seguridad Social prestaciones no contributivas.

${ }^{34}$ Cfr. Federación Empresarial Española de Asociaciones de Centros Especiales de Empleo. http://www.feacem.es/ (Consulta 29/01/2019).

35 BOE núm. 221, de 15 de septiembre de 1970.

${ }^{36} \mathrm{Cfr}$. p.e., http://www.guiaval.com/vlc/servicios/salud/discapacitados.html (Consulta 29/01/2019). 
Aunque introduce cambios importantes a favor de las personas con diversidad funcional a nivel asistencial, prestacional y de integración en los sistemas comunes (Seguridad Social, prevención, rehabilitación, educación y empleo), la ley sigue manteniendo un modelo médico de la discapacidad y nunca llegó a aplicarse plenamente. Según Rafael De Lorenzo ${ }^{37}$, la aplicación práctica de esta ley resultó devaluada por la falta de desarrollo normativo posterior, por la dispersión de las competencias entre entidades territoriales diver$\operatorname{sas}^{38}$, así como por la falta de compromiso financiero público. El fomento de la accesibilidad y la supresión de barreras, que la ley regula con cierto detalle (arts. 54 a 61), no se llegó a cumplir por falta de compromiso político a nivel local.

En referencia al AP, esta ley inaugura el subsidio por ayuda de tercera persona (art. 16 en relación con el art. 12 c), aunque establece como requisitos una muy baja capacidad económica y un alto grado de minusvalía (75\%), y ofrece a cambio cantidades pecuniarias ínfimas ${ }^{39}$. Además, en el art. 50 d) se establece como prioridad la permanencia en el entorno familiar.

Más adelante, en un productivo contexto normativo internacional sobre no discriminación y tras la Declaración de Madrid de 2002, dentro del año 2003 como Año Europeo de la Discapacidad, se promulga la Ley $51 / 2003$, de 2 de diciembre, de igualdad de oportunidades, no discriminación y accesibilidad universal de las personas con discapacidad (LIONDAU $)^{40}$. Esta ley ya no se basa solo en el art. $49 \mathrm{CE}$, de donde partía la LISMI, sino en el art. 14 y en el principio de igualdad proclamado en el art. 1.1, completado por el art.9.2, que obliga al Estado a remover los obstáculos para la consecución de la igualdad real ${ }^{41}$.

37 DE LORENZO GARCÍA, R., Discapacidad, sistemas de protección y Trabajo Social, Alianza Editorial, Madrid, 2007, págs. 234-243.

${ }_{38} \mathrm{En}$ base al art. 148, 20. ${ }^{\mathrm{a}} \mathrm{CE}$ y en relación con el citado art. 149.1.1. a , las Comunidades Autónomas pueden asumir competencias en servicios sociales, entre otras materias. En desarrollo de este artículo se promulga la Ley 7/1985 de 2 de Abril, reguladora de las Bases de Régimen Local, cuyo art. 25, k) adjudica a tales entidades la competencia en materia de "prestación de los servicios sociales y de promoción y reinserción social».

${ }_{39}$ Real Decreto 383/1984, de 1 de febrero, por el que se establece y regula el sistema especial de prestaciones sociales y económicas previsto en la Ley 13/1982, de 7 de abril, de integración social de los minusválidos (BOE, núm. 49, de 27/02/1984).

${ }^{40}$ BOE núm. 289, de 03/12/2003.

${ }^{41}$ CAMPOY CERVERA, I. 2004-2005a. «El reflejo de los valores de libertad, igualdad y solidaridad en la ley 51/2003, de 2 de diciembre, de igualdad de oportunidades, no discriminación y accesibilidad». Universitas: Revista de filosofía de derecho y política, n.1, 2004-2005, págs. 73-98. 
Con esta nueva Ley se incorporan al ordenamiento jurídico los principios de igualdad de oportunidades y no discriminación, junto con la accesibilidad universal. Se definen principios básicos como vida independiente, transversalidad de políticas o normalización (art. 2), discriminación directa e indirecta (art. 6) y acción positiva (art. 8.1). La ley fija planes y establece un calendario para la implantación de la accesibilidad, y ordena a las Administraciones Públicas emprender acciones de sensibilización, formación e innovación tecnológica, así como planes para garantizar la igualdad de oportunidades. Preveía también el establecimiento de un régimen de infracciones y sanciones, que se hizo realidad con la aprobación de la Ley 49/2007, de 26 de diciembre ${ }^{42}$. Crea además un Consejo Nacional de la Discapacidad ${ }^{43}$, en sustitución del anterior Consejo Estatal, como órgano consultivo, con la colaboración de asociaciones representativas del colectivo, y establece procedimientos de arbitraje y tutela judicial del derecho de igualdad.

Esta ley tuvo gran aceptación en el conjunto del colectivo de personas con diversidad funcional. En el art. 9.1 menciona ya la asistencia personal de un modo genérico, más tarde precisada en la Ley 39/2006, así como el principio de vida independiente.

En 2006 se promulga la Ley 39/2006, de 14 de diciembre, de Promoción de la Autonomía Personal y Atención a las personas en situación de Dependencia (LAPAD) ${ }^{44}$. Esta ley fue muy controvertida desde antes de su promulgación, y rechazada en gran parte por el MVI. Resulta significativo que no se esperara a analizar el texto de la Convención de Naciones Unidas, que se adoptó un día antes a la promulgación de esta Ley, ni se escucharan suficientemente las aportaciones de los afectados. También lo es que esta Ley haya pasado al lenguaje común como la "Ley de Dependencia», haciendo así una labor pedagógica inversa: en el imaginario social se reforzó la idea de dependencia, en lugar de la autonomía que, en teoría, se

42 Ley 49/2007, de 26 de diciembre, por la que se establece el régimen de infracciones y sanciones en materia de igualdad de oportunidades, no discriminación y accesibilidad universal de las personas con discapacidad. (BOE núm. 310, de 27/12/2007). Esta ley, junto con la LISMI y la propia LIONDAU, fueron derogadas al pasar a formar parte del Texto Refundido de la Ley General de derechos de las personas con discapacidad y de su inclusión social (TRLGPD): Real Decreto Legislativo 1/2013, de 29 de noviembre, por el que se aprueba el Texto Refundido de la Ley General de derechos de las personas con discapacidad y de su inclusión social. (BOE núm. 289, de 3 de diciembre de 2013).

43 Articulado mediante Real Decreto 1865/2004 de 6 de septiembre, por el que se regula el Consejo Nacional de la Discapacidad. (BOE núm. 216, de 7 de septiembre de 2004).

44 BOE núm. 299, de 15 de diciembre de 2006. 
pretendía fomentar. Toda la ley gira en torno a la dependencia, sin incluir otro tipo de necesidades humanas, como la mejora de la calidad de vida o la realización de los proyectos de vida personales que toda persona con diversidad funcional tiene el derecho de trazar, más allá de sus limitaciones.

Por otro lado, la ley nació con una gran carga de política partidaria. Esto provocó que su aplicación posterior, en manos de las Comunidades Autónomas como parte de los servicios sociales, hubiera desde el comienzo ralentizaciones o verdaderos boicots, según el color del gobierno autonómico, además de una desigualdad a nivel nacional ${ }^{45}$.

El SAAD se ha convertido, en la práctica, en un lento aparato clasificatorio de las personas en función de su dependencia. El deterioro del sistema ha sido evidente, incluso sin haber llegado a desarrollar nunca todas sus posibilidades. Los recortes en servicios sociales han provocado mayores retrasos, con revisiones a la baja para tener menos gasto social y con poca o ninguna posibilidad de elección por parte de quienes solicitan las ayudas ${ }^{46}$.

Son muchas las críticas formuladas contra la LAPAD en la literatura, pero cabe subrayar aquí la línea básica: mientras la Convención no utiliza el término «dependencia», poniendo las bases para el fomento de la autonomía de las personas con diversidad funcional, la LAPAD se dedica exclusivamente a regular la dependencia, ofreciendo prestaciones asistenciales o económicas, dentro de un modelo médico rehabilitador, contradiciendo su propio enfoque introductorio dentro del modelo social. El descontento general que ha provocado la LAPAD en un amplio sector de las personas con diversidad funcional representadas tanto por el CERMI como por el MVI, les lleva a proponer su reforma o sustitución por otra más acorde con los principios de la Convención.

\section{EL DERECHO FUNDAMENTAL A LA AUTONOMÍA DE LAS PERSONAS CON DIVERSIDAD FUNCIONAL}

Conviene comenzar recordando que no todas las normas jurídicas crean derechos subjetivos, sin que ello implique privarlas de

45 MAESTRO BUELGA, G., Marginación, Estado Social y Prestaciones Autonómicas, Cedecs, Barcelona, 1999.

46 GARCÍA HERRERA, M.A., "Veinticinco años de derechos sociales en la experiencia constitucional española», UNED Revista de Derecho Político, n. 58-59, 20032004, págs. 297-301. 
toda eficacia. Y el tratamiento de la discapacidad en la CE arranca del art. 49, que es uno de los principios rectores de la política social y económica que se recogen en el capítulo III del Título I; capítulo que, de acuerdo con el art. 53.3 CE, en principio no contiene derechos subjetivos:

... se trata de una serie de orientaciones y mandatos dirigidos a los poderes públicos, en términos que hacen particularmente difícil controlar su inactividad. (...) dependerá de cada precepto constitucional, y también del contexto en el que se invoque, la concreción de su concreto alcance normativo, que en ningún caso cabe fijar de antemano con carácter general (...) [el art.53.3] pretende evitar que del precepto constitucional se pretendan derivar derechos subjetivos tutelables por el juez al margen de la ley, pero no impide ni el control de la ley que haya infringido los mandatos constitucionales ni su interpretación en los términos más favorables a su pleno cumplimiento ${ }^{47}$.

En la LAPAD, la Exposición de Motivos n.3 dice sin embargo que el SAAD "configura un derecho subjetivo que se fundamenta en los principios de universalidad, equidad y accesibilidad» [subrayado nuestro]. Y en el art. 1.1 se dice:

La presente Ley tiene por objeto regular las condiciones básicas que garanticen la igualdad en el ejercicio del derecho subjetivo de ciudadanía a la promoción de la autonomía personal (...) mediante la creación de un Sistema (...) y la garantía de un contenido mínimo común [subrayados nuestros].

Pero en el Texto refundido de 2013 no aparece la expresión «derecho subjetivo», matizando en el art. 1 su aspecto relativamente menos garantista.

Tenemos, pues, una norma constitucional (art.49) que, en principio, no consagra derechos subjetivos, sino que impone tareas a los poderes públicos, concretando el mandato general de promoción de la libertad y la igualdad efectivas que contiene el art. 9.2 CE. Los Tratados internacionales ratificados por los Estados, entre ellos la Convención, tampoco consagran por sí mismos derechos subjetivos a favor de los ciudadanos de tales Estados, sino solo compromisos internacionales del Estado, sometidos a sistemas también internacionales de verificación y control que raramente prevén un mecanismo judicial de tutela al alcance de los particulares (con la excepción notable del Convenio Europeo de Derechos Humanos ${ }^{48}$ ). Las

47 GUTIÉRREZ GUTIÉRREZ, I. (dir.), op. cit., pág. p. 371. Incluso la palabra derecho que figura en alguno de los preceptos del cap. III estaría siendo usada de forma impropia (Ibid., p. 370).

48 Tribunal Europeo de Derechos Humanos, arts. 19 ss. 
normas internacionales y constitucionales exigen ciertamente el desarrollo de determinadas tareas públicas, cuyos contenidos objetivos sin embargo pueden variar según distintas opciones políticas, y han sido desarrolladas a través de leyes que, por su parte, podrían conformar derechos subjetivos. En este contexto cabe plantear, sin embargo, si todo ese entramado normativo puede ser interpretado en términos que permitan construir un verdadero derecho fundamental a la autonomía de las personas con diversidad funcional, o al menos reforzar la vinculatoriedad del mandato inicialmente impreciso del art. $49 \mathrm{CE}$.

\section{III.A. Derechos fundamentales}

Ello exige, en primer lugar, precisar mínimamente el concepto de derecho fundamental. Porque existe mucha confusión en el uso de la expresión, incluso al margen de las interferencias entre el plano jurídico de los derechos y el ético de los valores o principios, basado en un pacto social previo sujeto a cambios históricos. A veces se usa por parte del propio Tribunal Constitucional en un sentido restringido, referido a la Sección primera del Capítulo II del Título I de la Constitución, y otras en un sentido más amplio, comprensiva del todo el Capítulo II o incluso de todo el Título ${ }^{49}$. En España, según una clasificación estricta y tradicional ${ }^{50}$ y a la luz del art. $53 \mathrm{CE}$, nos encontramos en dicho Título con tres niveles de protección:

a) Derechos garantizados al más alto nivel: los contenidos en la sección primera del Capítulo II de Título I (arts. 15 a 29), más los arts. 14 y $30.2 \mathrm{CE}$. Estos derechos son de aplicación directa, sin necesidad de desarrollo legislativo, al menos en su nivel esencial (STC 75/1982), y en su caso pueden ser garantizados mediante el recurso de amparo ante el Tribunal Constitucional. Esta protección del amparo «no alcanza a los derechos contenidos en otras normas, especialmente en Tratados internacionales o en el Derecho comunitario europeo» ${ }^{51}$.

49 CRUZ VILLALÓN, P., «Formación y evolución de los derechos fundamentales», Revista Española de Derecho Constitucional, vol. 9, n. 25, 1989, pág. 37.

${ }^{50}$ NÚÑEZ RIVERO, C. et al., Teoría del Estado Constitucional. Universitas, Madrid, 2010, p. 328.

${ }^{51}$ NÚÑEZ RIVERO, C. et al., ibid. págs. 212 y 202. Cfr. Ley Orgánica 2/1979, de 3 de octubre, del Tribunal Constitucional., arts. 10 a) y 27 c) (BOE, núm. 239, de 05/10/1979). 
b) Derechos garantizados «a nivel medio»: los pertenecientes a la sección segunda del mismo capítulo II (arts. 30 a 38), que no tienen las garantías que hemos especificado para los anteriores, pero que sí están protegidos, al igual que ellos, por la reserva de ley: solo la ley puede regular su ejercicio y limitarlos, respetando en todo caso su contenido esencial.

c) Principios de política social y económica con «protección mínima», en el Capítulo III del mismo Título I (arts. 39 a 52). Serán desarrollados por ley, y solo pueden alegarse ante jurisdicción ordinaria según lo que dispongan estas leyes. Al no garantizarles el art. 53.3 el contenido esencial frente al legislador, como hace el art.53.1, no se les puede considerar derechos fundamentales.

Pero «algunas normas de la Constitución situadas incluso fuera del Título I, por estar su contenido vinculado a un derecho fundamental recogido en el Capítulo II de dicho Título, se consideran como contenido de tal derecho fundamental ${ }^{52}$. Ello difumina no solo la diferencia entre normas en función de su ubicación, sino incluso la distinción entre las que recogen un derecho y las que no, al menos cuando el contenido de estas últimas está vinculado a un derecho fundamental del Capítulo II del Título I CE, en cuyo caso se le aplican garantías propias de este derecho. En cada caso habrá que analizar, por tanto, la existencia y el alcance de una posible conexión con un derecho fundamental.

Por lo demás, los derechos fundamentales pueden ampliar su alcance y proyección merced al desarrollo legislativo; la ley puede establecer muy diversas medidas de protección y promoción. De este modo, el objeto y el contenido de los derechos acaban siendo definidos al menos parcialmente por el legislador, con la consecuencia de que la lesión de la norma legal que configura el derecho se considera a ciertos efectos como vulneración del propio derecho constitucional $^{53}$.

Los tratados internacionales en España, una vez publicados en el $B O E$, forman parte del ordenamiento interno (art. $96 \mathrm{CE}$ ); de modo que los derechos reconocidos en esos tratados también deben ser tutelados por los jueces. En ese sentido, se equiparan a las leyes a las

52 GUTIÉRREZ GUTIÉRREZ, I. (dir.), op. cit., pág. 270. Subrayado nuestro.

${ }^{53}$ Ibidem. Debe recordarse aquí, en todo caso, tanto con referencia a la llamada «reserva de lo posible» como con el principio de irreversibilidad de las conquistas sociales, que el art .4 PIDESC solo admite límites por ley, compatibles con los derechos y con el único fin del bienestar general. 
que nos acabamos de referir, aunque con una particular preferencia de aplicación sobre ellas. Sin embargo, el art. 10.2 CE establece además que los tratados internacionales sobre derechos humanos han de ser utilizados como criterio para la interpretación de las normas constitucionales en la materia; de modo que, al interpretar los derechos fundamentales reconocidos por la Constitución, han de tenerse en cuenta las obligaciones que ha contraído España para la garantía de los derechos humanos, de forma que la protección de los derechos fundamentales sirva para cumplir efectivamente esos compromisos. En esa medida, los preceptos del Título I de la Constitución asumen como verdadero contenido constitucional, por vía de interpretación, el que deriva de los Tratados internacionales ratificados por España en las correspondientes materias.

Con todo ello se difumina de nuevo la frontera entre derechos constitucionales, derechos humanos y derechos subjetivos de origen legal, aunque siempre seguirá siendo necesario el punto de apoyo de una disposición constitucional para identificar la presencia de un derecho fundamental. Y esto es particularmente necesario en el caso de las personas con diversidad funcional, a quienes, con demasiada frecuencia, se les considera como meramente dependientes, negándoles el derecho a su propia personalidad y todos los derechos que se derivan de ello.

\section{III.B. Derechos sociales}

El problema no está solo en la identificación de un derecho fundamental, sino en las garantías con las que se le dota. Algunos autores denuncian en general la «ausencia de mecanismos de garantía de los derechos sociales» como «una omisión inconstitucional que el juez puede legítimamente colmar» ${ }^{54}$. Y en ese contexto se analiza también si la distinción entre unos derechos y otros en función de sus garantías se apoya en cierto concepto de subjetividad jurídica, que puede seguir primando el aspecto individual frente el aspecto colectivo, cuando en el sujeto coinciden necesariamente los dos elementos: el de sus propios intereses y el de la igualdad de todos, que hace inseparables los unos de los otros, adquiriendo pronto un carácter objetivo ${ }^{55}$.

${ }^{54}$ ESCOBAR ROCA, G., «Recensión: Luigi Ferrajoli, Derechos y garantías. La ley del más débil, Trotta, Madrid, 1999», Derechos y libertades: Revista del Instituto Bartolomé de las Casas, n. 9, 2000, pág. 534.

55 DE CABO MARTÍN, C., «El sujeto y sus derechos». Teoría y Realidad Constitucional, n.7, 2001, págs. 122 y 125. 
Ello entronca con una perspectiva histórica sin duda válida en el contexto del análisis teórico y crítico. En efecto, los derechos fundamentales sirvieron inicialmente para defender la libertad privada, en favor de los intereses burgueses, pero hoy, en el nuevo Estado social, la intervención estatal ha de procurar la reserva de un derecho igual para todos con un sentido dinámico de reajuste del derecho ${ }^{56}$. Hoy una respetable mayoría de autores se decanta por su armonización en las nuevas circunstancias históricas, pudiéndose generar nuevas facetas de los derechos individuales que pueden necesitar una mayor intervención del Estado para su efectividad ${ }^{57}$.

La jurisprudencia desarrolla así una importante labor en la concreción del contenido de los derechos, cuya vaguedad estimula a los interesados a expresar sus necesidades y al Estado a ir perfilando sus normativas en relación con ellas; los jueces examinan la idoneidad de las medidas públicas para hacerlos eficientes. Pero es necesario aprovechar las vías de exigibilidad (directa o indirecta ${ }^{58}$ ) que ofrece el Derecho.

\section{CONCLUSIONES Y PROPUESTAS: LA CONSTRUCCIÓN DEL DERECHO}

Bobbio nos prevenía de que «los derechos humanos, por muy fundamentales que sean, son derechos históricos, es decir, nacen gradualmente, no todos de una vez y para siempre, en determinadas circunstancias, caracterizadas por luchas por la defensa de nuevas libertades contra viejos poderes» ${ }^{59}$. La lucha concreta por los derechos de las personas con diversidad funcional es algo relativamente reciente, si lo comparamos con su multisecular status de abandono y marginación ${ }^{60}$. Sus logros han sido más bien modestos, en relación a la autonomía personal, pues van poco más allá de la mera supervivencia, con enormes diferencias entre el centro y la periferia. Tras cerca de un siglo de lucha reivindicativa, creemos urgente tomar en serio una reforma en profundidad de nuestro Derecho, de tal modo que haga posible el desarrollo integral de todas las personas. La exi-

56 GRIMM, D., Constitucionalismo y derechos fundamentales. Trotta, Madrid, ed.2006, págs. 105-106.

57 Cfr. por todos ESCOBAR ROCA, G. (Dir.), Derechos sociales y tutela antidiscriminatoria, Thomson Reuters Aranzadi, Cizur Menor (Navarra), 2012.

${ }_{58}$ La exigibilidad indirecta aprovecha la justiciabilidad de otros derechos. ABRAMOVICH y COURTIS dedican un amplio apartado a este tema con referencia sobre todo al Derecho civil (op. cit., págs. 168-248).

59 BOBBIO, N. 1991. El tiempo de los derechos, Sistema, Madrid, 1991, págs. 17-18.

${ }^{60}$ AGUADO DÍAZ, A.L., op. cit. 
gencia de reformas constitucionales se viene pidiendo desde diferentes ámbitos sociales en proporción directa a los recortes vividos en los últimos decenios. Es un momento idóneo para trabajar en ello.

Con respecto a la cuestión que nos ocupa, según el rápido recorrido histórico reseñado y según el baremo de garantías al que hemos aludido, los mayores esfuerzos reivindicativos a corto plazo, deberían centrarse en el refuerzo constitucional del derecho a la autonomía de las PDF. Para ello habría que acudir a los derechos reconocidos en ella como fundamentales y explicitar su conexión con los referidos a la diversidad funcional. Un paso sencillo sería recurrir al artículo 14 y añadir al listado de motivos de discriminación la diversidad funcional, puesto que en este caso se podría desarrollar con mayor fundamento cualquier legislación al respecto, como ha ocurrido con la discriminación por sexo o raza, que social y jurídicamente han sido más elaborados y asimilados. Sería además conveniente reforzar su inclusión en este artículo subrayando la conexión evidente con otros derechos reconocidos fundamentales como el derecho a elegir residencia (art.19), a la participación (art.23) o a la educación/pleno desarrollo de la personalidad (art.27).

Por su parte, el art. 49, único que se refiere explícitamente a la diversidad funcional, debería cambiar su término disminuido por otro más acorde a nuestra actual sensibilidad social, como puede ser el que empleamos nosotros a propuesta del MVI. También puede reforzar la igualdad en derechos que proclama, subrayando la discriminación que supondría no hacerlo por razón de su diversidad. Un argumento bidireccional que no quede en una mera declaración de principios. Por otro lado, el art. 53, que reparte las garantías constitucionales con diverso peso, también puede incluir el artículo 49 modificado entre los de mayor garantía, junto con otros aspectos que se valoran mayoritariamente en nuestra sociedad plural, como puede ser el caso de exigir una regulación positiva de los movimientos migratorios, en base a los derechos humanos reconocidos por la Constitución como fuente inspiradora de interpretación.

A partir de ahí son muchas las consecuencias legales que se pueden afrontar, como la formulación de una nueva ley sobre la autonomía de las personas con diversidad funcional distinta a las leyes de protección de las personas dependientes en razón de su edad, enfermedad, etc., dentro de los epígrafes de salud o correspondientes. La nueva ley debería ser general a nivel estatal, no dejándolo prácticamente todo a las Autonomías, precisamente por razones de libre movilidad e igualdad de derechos, pues, de hecho, se ha convertido en una vía de escape de los compromisos gubernamentales, falta de 
control en los recursos empleados en las autonomías y multiplicidad de normativas según los cambios políticos o circunstanciales.

El texto refundido, que intentó pasar en 2013 como una nueva Ley General de derechos de las personas con discapacidad y su inclusión social, como su propio nombre indica, no añadió nada a lo dicho hasta 2003, aunque eso sí, tiene preámbulo con alto contenido social, que nada tiene que ver con el articulado que viene después y que procede de años muy anteriores a la Convención de 2006, sobre todo en referencia a la LISMI, de donde provienen las mayoría de prestaciones económicas. Una verdadera nueva ley no tendría que renunciar a las prestaciones en ella registradas, pero eso sí, actualizando y unificando todas estas prestaciones y baremos en relación a una verdadera reforma del fondo social y de derechos humanos que configurase la nueva ley. El actual sistema que mezcla prestaciones antiguas y nuevas, incompatibilizándose entre sí, no hace sino poner en evidencia la falta de esfuerzo político en valorar la autonomía de las PDF. Se puede decir que a día de hoy, es preferible una de las antiguas prestaciones contributivas por la Seguridad Social a las nuevas prestaciones del SAAD, excesivamente limitadas, aunque formalmente encaminadas a conseguir el derecho subjetivo de autonomía de las personas con discapacidad. El SAAD ofrece medios incongruentes con sus fines declarados.

Pero a medio plazo, habría que reforzar a nivel internacional en primer lugar la fuerza vinculante de las ratificaciones de los Tratados. Estos suelen ir acompañados de protocolos facultativos, como es el caso de la Convención de 2006, que permiten la no aceptación de auditorías externas internacionales. Un segundo paso importante sería suprimir la asimetría entre los dos Pactos, dejando en la práctica los derechos sociales como derechos de segunda. Hoy en día no tiene sentido hacer esa distinción ante una nueva conciencia social nacida desde el incremento global de la desigualdad. El derecho a la autonomía de las personas con diversidad debería considerarse no solo un derecho social sometido a los principios de progresividad y reserva de lo posible, sino también como un derecho civil inalienable.

El tercer paso, dentro de este contexto global económico y tecnológico, que impone indiscriminadamente sus leyes, tendría que ser una legitimación expresa de la autoridad de las Instituciones internacionales a todos los niveles, sobre todo jurídicos y políticos, más allá de los convenios regionales o bilaterales, también con poder sancionador. La experiencia de UE demuestra que es posible superar barreras nacionales sin anular las diferentes culturas y enriqueciéndose con la convivencia de ideales y derechos democráticos. Un ex- 
clusivo criterio económico ya sabemos por experiencia que no lleva a buen fin, como vemos en las tragedias migratorias, las dictaduras de muchos países, los conflictos bélicos etc. Si vivimos en un mundo global y queremos seguir siéndolo, habrá que globalizar también los derechos. No podemos seguir mirando hacia otro lado. El poder sancionador de la comunidad internacional es necesario si queremos mínimamente conseguir algo de lo previsto en los Tratados.

Personalmente pensamos que la concepción del mundo como Naciones Unidas es altamente positiva y portadora de paz. Las autonomías nacionales no existen de hecho al ser dependientes de estructuras económicas globales. Se trata de cambiar la esencia misma de la globalización, del mismo modo que, a nivel regional, se transformó una Comunidad Económica Europea en una Unión Europea, eso sí, con muchos altibajos y cuestiones pendientes por resolver. Este fortalecimiento a nivel internacional no cabe duda de que influiría directamente en los grupos más vulnerables, pues, como hemos visto en nuestra breve exposición histórica, las grandes iniciativas en función de los derechos humanos han surgido precisamente de la unión entre naciones como reacción a las grandes guerras, fruto de unos intereses nacionales irresponsables con el ser humano.

En este contexto global, el derecho a la autonomía personal, a poder decidir, se da por sentado en toda persona libre ${ }^{61}$, y no se entiende que no se reconozca y regule como un derecho fundamental también para las personas diferentes. Precisamente la universalización de la cultura en nuestra sociedad red ${ }^{62}$, nos ha hecho más conscientes de la universalización de los derechos, y a la vez de la falta de responsabilidad de los Estados en la garantía de estos derechos. Por tanto, los Estados y el Derecho que los sustenta, deben evolucionar hacia un renovado pacto social (universal) si quieren seguir manteniendo la legitimidad por la que fueron creados.

\section{REFERENCIAS BIBLIOGRÁFICAS}

Abramovich, V. y Courtis, CH., Los derechos sociales como derechos exigibles, Trotta, Madrid, ed.2014.

Aguado Díaz, A.L., Historia de las Deficiencias, Escuela Libre Editorial, Madrid, 1995.

61 ÁLVAREZ MEDINA, S., La autonomía de las personas. Una capacidad relacional, CEPC, Madrid, 2018.

${ }^{62}$ CASTELlS, M. (ed.), La Sociedad Red: una visión global, Alianza, Madrid, 2006. 
Alcaín Martínez, E. (dir.) y Álvarez Ramírez, G. (coord.), La Convención Internacional sobre los derechos de las personas con discapacidad. De los derechos a los hechos, Tirant lo Blanch, Valencia, 2015.

Alemán Bracho, C. (coord.), Fundamentos de servicios sociales, Tirant lo Blanch Valencia, 2010.

Álvarez Medina, S., La autonomía de las personas. Una capacidad relacional, CEPC, Madrid, 2018.

BobBio, N. 1991. El tiempo de los derechos, Sistema, Madrid, 1991.

CAmpoy Cervera, I., «La construcción de un modelo de derechos humanos para niños, con o sin discapacidad», Derechos y libertades: Revista del Instituto Bartolomé de las casas, n. 37, 2017, págs. 131-165.

CAmpoy Cervera, I., «El reflejo de los valores de libertad, igualdad y solidaridad en la ley 51/2003, de 2 de diciembre, de igualdad de oportunidades, no discriminación y accesibilidad». Universitas: Revista de filosofía de derecho y política, n.1, 2004-2005, págs. 73-98.

CARBOnell APARICI, G.J., «La asistencia personal, una herramienta saludable para las personas con diversidad funcional», en MARcos Del Cano, A.M. (dir.) , El derecho a una asistencia sanitaria para todos: Una visión integral, Dykinson, Madrid, 2017, pp. 411-425.

CARbonell Aparici, G.J., La figura del asistente personal en el Movimiento de Vida Independiente: La experiencia en la Comunidad Valenciana, Tesis Doctoral (en línea), Madrid, UNED, 2018. Acceso: http://e-spacio.uned.es/fez/eserv/tesisuned:ED-Pg-DeryCSoc-Gjcarbonell/CARBONELL_APARICI_Gonzalo_Jose_Tesis.pdf

CASTElls, M. (ed.), La Sociedad Red: una visión global, Alianza, Madrid, 2006.

CERMI. El CERMI plantea la constitucionalización como fundamentales de los derechos sociales, CERMI, Madrid, 20/08/2015. Acceso: https://www.cermi.es/es/actualidad/noticias/el-cermi-plantea-laconstitucionalizaci\%C3\%B3n-como-fundamentales-de-los-derechos (Consulta (27/01/2019).

CERMI. El CERMI pide en el Senado incluir los derechos sociales como fundamentales en la Constitución, Madrid, CERMI, 20/09/2017. Acceso: https://www.cermi.es/es/actualidad/noticias/el-cermi-pideen-el-senado-incluir-los-derechos-sociales-como-fundamentales-en (Consulta 26/01/2019).

Cruz Villalón, P., "Formación y evolución de los derechos fundamentales», Revista Española de Derecho Constitucional, vol. 9, n. 25, 1989, págs. 35-62. 
De Cabo Martín, C., La crisis del Estado Social, PPU, Barcelona, 1986

De Cabo Martín, C., "El sujeto y sus derechos», Teoría y Realidad Constitucional, n.7, 2001, págs. 117-135.

De Cabo Martín, C., Teoría constitucional de la Solidaridad, Ediciones Jurídicas y Sociales, S.A., Madrid, 2006.

De Lorenzo García, R., Discapacidad, sistemas de protección y Trabajo Social, Alianza Editorial, Madrid, 2007.

Escobar Roca, G., «Recensión: Luigi Ferrajoli, Derechos y garantías.

La ley del más débil, Trotta, Madrid, 1999», Derechos y libertades:

Revista del Instituto Bartolomé de las Casas, n. 9, 2000, págs. 521534.

Escobar Roca, G. (dir.), Derechos sociales y tutela antidiscriminatoria, Thomson Reuters Aranzadi, Cizur Menor (Navarra), 2012.

European Union Agency For Fundamental Rights (FRA), Fundamental Rights Report 2018, FRA, 2018.

Ferrajoli, L., Derechos y garantías. La ley del más débil, Trotta, Madrid, ed. 2004.

FERreIRA, M.A.V., «De la minus-valía a la diversidad funcional: Un nuevo marco teórico-metodológico», Política y Sociedad, vol. 47, n. 1, 2010, págs. 45-65.

FVID. Carta abierta a Luis Cayo Pérez Bueno, presidente del Cermi estatal, FVID, 7 diciembre, 2018. Acceso: http://forovidaindependiente. org/carta-abierta-a-luis-cayo-perez-bueno-presidente-del-cermi-estatal/ (Consulta 26/01/2019).

García Herrera, M.A., "Veinticinco años de derechos sociales en la experiencia constitucional española». UNED Revista de Derecho Político, n. 58-59, 2003-2004, págs. 277-304.

García Pons, A., «El artículo 12 de la Convención de Nueva York de 2006 sobre los Derechos de las Personas con Discapacidad y su impacto en el Derecho Civil de los Estados signatarios: el caso de España», $A D C$, tomo LXVI, fascículo. I, 2013

GaRgarella, R., «Primeros apuntes para una teoría sobre los derechos sociales. ¿Es posible justificar un tratamiento jurídico diferenciado para los derechos sociales e individuales?». Jueces para la democracia, n. 31, 1998, págs. 11-15.

Grimm, D., Constitucionalismo y derechos fundamentales. Trotta, Madrid, ed.2006. 
Gutiérrez GutiérRez, I. (dir.), Elementos de Derecho constitucional español, Marcial Pons, Madrid, ed. 2015.

Hesse, K., Grundzüge des Verfassungsrechts der Bundesrepublik Deutschland, C. F. Müller GmbH, Heidelberg-Karlsruhe, ed. 1978.

Hesse, K., "Significado de los derechos fundamentales», en BENDA, E. et al. (eds.), Manual de Derecho Constitucional, Marcial Pons, Madrid, ed. 2001, págs. 97 ss.

Jiménez LaRA, A. y Huete García, «Políticas públicas sobre discapacidad en España. Hacia una perspectiva basada en los derechos», Política y Sociedad, vol. 47, n.1, 2010, págs. 137-152.

Kelsen, H., Teoría pura del Derecho, UNAM, México, ed. 1986.

LóPez Pina, A. y Gutiérrez GutiérRez, I., Elementos de derecho público. Madrid/Barcelona: Marcial Pons, Ediciones jurídicas y sociales, S.A., Madrid/Barcelona, 2002.

Maestro Buelga, G., Marginación, Estado Social y Prestaciones Autonómicas, Cedecs, Barcelona, 1999.

Maestro Buelga, G., «El Estado Social 40 años después: la desconstitucionalización del programa constitucional», Revista de Derecho Político, n. 100, 2017.

Nino, C.S., "La filosofía del control judicial de constitucionalidad», Revista del Centro de Estudios Constitucionales, n. 4, 1989, págs. 79-88.

NúÑEz Rivero, C. et al., Teoría del Estado Constitucional. Universitas, Madrid, 2010.

Palacios, A., El modelo social de discapacidad: orígenes, caracterización y plasmación en la Convención Internacional sobre los Derechos de las Personas con Discapacidad, Cinca, Madrid, 2008.

PERLINGEIRo R., « ¿La reserva de lo posible se constituye en un límite a la intervención jurisdiccional en las políticas públicas sociales?», Estudios Socio-Jurídicos, vol. 16, n.2, 2014, págs. 181-212.

SANJosÉ GIL, A., «El primer tratado de derechos humanos del siglo XXI: La Convención sobre los derechos de las personas con discapacidad», Revista electrónica de estudios internacionales, $\mathrm{n}$. 13, 2007.

Toboso Martín, M. 2017, «Capacitismo» en Platero, R.L. et al. (eds.), Barbarismos queer y otras esdrújulas, Bellaterra, Barcelona, 2017, pp. 73-81. 